\title{
AMELIORATING THE CHALLENGES FACING NIGERIANRESEARCHERS; FOCUS ON ABSTRACT WRITING IN PSYCHOLOGICAL RESEARCH
}

FAGBOHUNGBE, Oni Bamikole, PhD, JAYEOBA, Foluso Ilesanmi, PhD

Department of Psychology, Faculty of Social Sciences, University of Lagos, Nigeria ${ }^{1}$, Department of Industrial Relations and Personnel Management, Faculty of Management Sciences, Lagos State University, $\mathrm{Ojo}^{2}$

$$
\frac{\text { ofagbohungbe@ } \text { unilag.edu.ng }^{1} \text {, foluso.jayeoba@ lasu.edu.ng }{ }^{2}}{\text { DOI: 10.36108/ljerhrm/8102.01.0153 }}
$$

\begin{abstract}
The focus of this paper is on abstract writing in research. It has been observed over the years that many researchers, particularly many Nigerian research students are just not at home with writing abstract after carrying out a research. Yet many do awkwardly present their abstract with the research proposal even when the study is yet to be done. What happens when eventually they finished the study, anxiety and confusion take over because they do not know in precise form what the structure and content of an abstract are. Therefore, readers and assessors are left to wonder whether what is before them is statement of the problem, summary of findings or literature review.Based on the above observations, this paper has clearly explained "research" and "abstract" from their proper conceptual perspectives by providing useful guidelines for acceptable abstract writing, appropriate length for abstract and the pitfalls to avoid when writing one.
\end{abstract}

Key words: Psychological Research, Abstract.

\subsection{Introduction}

The focus of the paper is to discuss abstract writing in psychological research. Psychology, like other disciplines carry out elaborate scientific research in order to find solution to the problems and other challenges confronting humanity. The fact must be appreciated that a profession is committed to the task of enlarging the body of knowledge it applies to the problems and troubles with which it deals. Therefore, any profession which is not rooted in systematic knowledge is a self-contradiction, a myth, rather than reality (Merton, 1968). The means to that knowledge is research report which communicates the outcomes of a research already concluded. A research report is made up of interrelated components or parts that have its own structure. One of such component parts is the "abstract".

An abstract is a very important component in any psychological research. It has its own structures which are uniquely put together because it contains the totality of the summary of the research work.

However many researchers, particularly research students are usually at sea for lack of adequate knowledge of abstracts and its structure. Hence they experience serious anxiety. Some become so desperately depressed that they result into engaging the services of research - touts.

This accounts for why this paper is devoted to abstract writing in psychological research. When the content and structure of an abstract is violated, the consequential effects include the following:

1. Submerging or blockade of good research work,

2. Distortion of the relevance of the research work, and

3. Misleading of potential or intending users of the research work and obliterating both the academic quality and the social values of research work.

Therefore, this paper through in-depth review of abstracts across varied reputable psychological journals has been able to extract and present to researchers and potential researchers how to handle the abstract segment of their research work. As part of the introduction to this work, it pertinent to inform readers that there are different types of abstracts. In reference to University of Southern California libraries, there are four types of abstracts such as:

i. Critical Abstracts: This type describes main findings and in addition does the following - critically discuss the validity, reliability how complete and relevant the work is, evaluate and compare the work with other works in the same subject area. Since it dabbles into almost all aspects of the research work, its length is usually between $400-500$ words and this accounts for why this type of abstract is rarely used in research, particularly psychological research. The issue here is, if the abstract contains this much, what will be left in the body of the entire work that will warrant going through again.

ii. Descriptive Abstract: This type describes the outline of the work by emphasizing the key words found in the study and may briefly mention the purpose and method employed in the study. In addition it will not make a 
critique of the work neither will it include the result of the work. Since it provides brief information, its length is usually about 100 words.

iii. Informative Abstract: This type of research abstract authenticates the entire work mirroring the work itself. It enables the researchers to present and explain all the cogent components of the results of the research. It describes the purpose, method, scope, result, conclusion and recommendations. Due to the volume of information it has to provide, its length varies across departments and disciplines. Usually the length is about 300 words. It is a widely accepted abstract format/type.

iv. Highlight Abstract: This type is specifically written to attract readers' attention. There is never any pretense on the part of the writer that it is written to provoke or instigate the attention of the reader. It involves the use of catching words whether it is a component or not in the report itself. Therefore it is never a complete abstract because it is written purposefully to satisfy the desire of the writer.

Having discussed types of abstracts, the pertinent question becomes; from the focus of the present research 'abstract writing in psychological research", which type of abstract is the most suitable for abstract writing in psychological research. The answer to the question, without any equivocation is "informative abstract"

\subsection{Conceptual Explanation}

All disciplines have its own concept which forms its language of communication (Pitkin \& Brangan, 1998). This informs why people's understanding is any discipline is a function of their understanding of the concepts that define that particular discipline. From the topic above emerge two important concepts. These are "abstract' and 'psychological research".

These two concepts are therefore defined and explained. Logically, let us start with psychological research.

\subsubsection{Psychological Research.}

Nachmias and Nachmias (1982) defined psychological research as a behavioral quest for new knowledge pertinent to an identified area of interest or through the application of the scientific approach or process. Characteristically, it is an organized investigation of a problem and a systematic approach to its solution through total removal or alleviation of such problem which could be simple or complex, immediate or long term (Kaplan, \& Saccuzzo, 2001).

Research are of different types ranging from basic or pure research, applied research, evaluation research, historical research, action research, descriptive research case study research, to experimental research. One thing common to all these types of research is that their report must carry an "abstract".

\subsubsection{Abstract}

An abstract is a summary of a research article, thesis, review, conference proceeding or a manuscript (Dooley,1984; Hopewell, Clarke, Wager, Middleton, Altman, \& Schulz, 2008)). Characteristically, an abstract has the following:

1. An abstract is not written until the whole research work has been completed.

2. It is always presented before the main report and because it appears at the beginning, it constitutes the gateway to the main report

3. It is the summary of what is contained in the research work and therefore it is usually very brief, hence it is presented in a summary form.

4. It has restricted number of words which is between $250-350$ words. However there is what is called Extended Abstract of between $3-4$ pages but this is usually conference papers for special reasons.

5. It bears or carries the purpose of the work or paper.

6. It contains also, the research design, participants, selection, sampling technique, few of the hypotheses where they are many major finding.

7. It is always written in a way that makes it look distinct from the main report. Many disciplines present it in "italics", while others leave it bold or in block form.

However, user of this work should note that there is what is called book of abstract or index. This is quite different from abstract in psychological research. This is a situation in which a body of literature are compiled for a particular subject. Various academic disciplines do engage in abstracting and indexing services. 
Having discussed the characteristics of an abstract, it is important at this point to display a typical abstract. The box below precisely shows that:

This field experimental study was carried out to investigate the effect of eye-dominance on performance in visual search tasks and the implication for camera user in Nigeria. In carrying out the study, a $3 \times 3$ factorial design was used. The visual search task used in the study was the searching of a specific number or numbers within arrays of numbers. Two hypotheses were tested; one of which states that, in a visual search task, the dominant-eye will search more items than the non-dominant one. For data gathering, 60 participants drawn from across different and nonprofessional groups within the city of Lagos were used. A repeated measure factorial design was adopted and as a result, each participant was made to go through 27 sessions of 30 seconds each during the experimental studies. For data analysis, Duncan's multiple range tests and Analysis of Variance were used. All the hypotheses were supported. The most spectacular of the finding being that the dominant eye searched significantly larger number of items than the non-dominant eye. The result prompted the recommendation that camera users should endeavor to identify which of their eyes (left or right) is dominant and use such dominant eye to view the camera when talking pictures.

The box above contains a typical abstract for an experimental research study. There will be need to refer to this box again when discussing the structure of an abstract.

\subsection{The Structure of an Abstract}

Just like the whole report is structured, so also is the abstract. Figure I below explains the structure of a typical abstract

\section{Fig 1: A typical Structure of an Abstract}

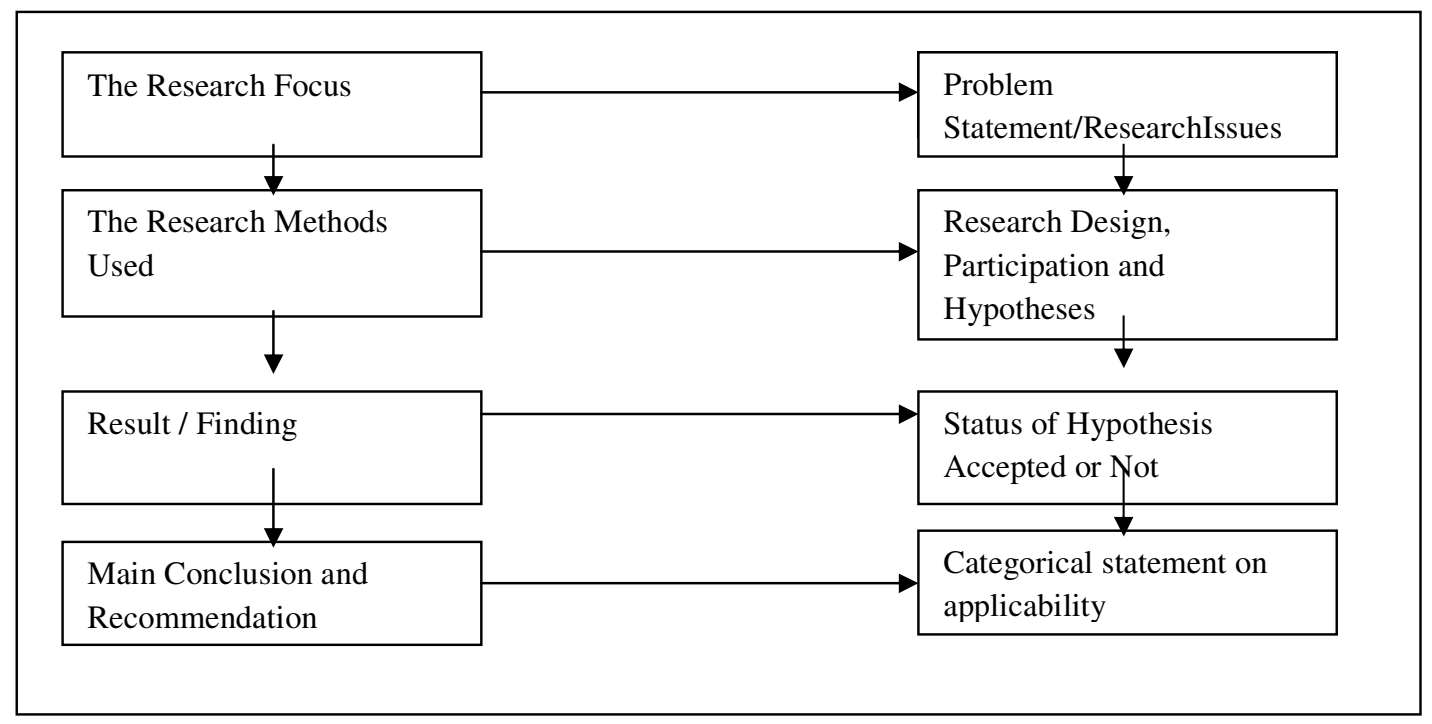

Source: Fagbohungbe, 2018

Source: Fagbohungbe (2010)

Figure1 shows a typical structure of an abstract. Note should be taken of the sequential interrelatedness between the components of the abstract. This implies that a researcher cannot discuss the focus after methods or the method after finding.

\subsection{Importance Abstract in Psychological Research}

Abstract plays very important roles in psychological research. These roles are discussed under the following subheadings:

i. Importance to Research

ii. Importance to Researchers

iii. Importance to users of Research outcomes. 


\section{Importance of Research}

i. It is the point of entry to academic research papers: Researchers in quest of relevant literature review usually peruse the abstract first before going into the body of the entire work.

ii. It provides the summary of entire research report. As a summary, it guides and saves the time of potential users.

iii. It reveals the intellectual originality and social importance of the research in relation to reality through its recommendation

iv. It directs potential users: Intending users are enabled to take quick decision as to whether to continue or not continue by quickly reading the abstract.

v. It serves as a table of content to the experienced users of research

vi. Out comes: In the search or quest for information the experienced users of research outcomes consult the abstract first.

vii. It provides information on the focus, purpose, design and paraphrased the methodology for would be users as well as well as spontaneous assessment of the worth of the research.

viii. It can communicate complex research outcome: Abstracts simplifies complex research outcomes.

\section{Importance to Researchers}

i. It provides significant selling point for their research findings.

ii. It enables researchers to widely present their research to end users.

iii. It assists researchers in patenting their research report

iv. It protects the work of researcher under copyright law

v. It creates awareness for their research work

vi. It gives researches confidence on the relevance of their work

\section{Importance to Users of Research Outcomes}

i. It appropriately directs the attention of user to needed research areas

ii. It saves the time of users since they can quickly identify what they need.

iii. It allows potential users to sift and make their choices

iv. It allows users to easily identify the purpose of research.

Having done with the importance of abstract in psychological research, let attention be shifted to another important aspect of the paper. Let us therefore discuss guidelines to effective abstract writing.

\subsection{Guidelines to Acceptable Abstract Writing}

1. Have a deep Knowledge and understanding of the problem you have investigated.

2. Make sure you are able to clearly identify the core components of the research work such as purpose/objective, participants, selection technique, hypotheses, instrument for data gathering, statistics used finding, conclusion and recommendation. Importantly, note that where the important items in these components are many, you just mention few of them in your abstract. For example if you have as many as five hypotheses you are ok with stating one or two. This will enable you to comply with the required number of words and maintain the brief nature of abstract. Also by doing the above you won't appear to be writing the report twice.

3. An abstract is not a duplication nor a regurgitations of the entire research, therefore be brief by writing only the essential components

4. Write your abstract in a sequential order that follows the research process (see figure 1pg. 4). Do not discuss finding before purpose and recommendation before finding

5. Check and recheck to make sure you communicate within the content of your report. Never claim in the abstract what is not available in the body of the report.

6. Write the abstract last after the completion of the research work. It is absurd when a supervisee brings to his supervisor a research proposal and there lies the abstract of a research which is just about to start. Such action or approach is akin to working from answer to question.

In addition to the above guidelines, the use of the following question can assist your abstract wiring:

i. What is the problem and why bother about it (Motivation Integration)

ii. What makes the problem qualifies for investigation (Problem Statement integration)

iii. How do I get the problem solved ( Method/ Approach Integration)

iv. What is the Finding (Result Integration)

v. What are the implications of the finding ( Conclusion/ Recommendation Integration) 


\subsection{Appropriate Length of Abstract}

We have hammered so much on the brief nature of abstract. I can hear you asking, what is the appropriate or the acceptable length? The length varies from institution to institution, from department to department and from publisher to publisher (Chidi, 2013). The typical abstract length ranges from 250-350 words or as may be specifically prescribed by convention of degree awarding department or university, such as often prescribed for doctoral students with respect to their thesis. To those using pages, it ranges from half (1/2) to one (1) page at most.

Any abstract that extend beyond one page is no longer a summary (brief) but a report (University of Southern California (U.S.C Libraries)). The only exception to this is Extended Abstract (see page 3). Therefore, as a researcher, your responsibility is to know and comply with the format/requirements of your department, institution or the publisher.

\subsection{Pitfalls to Avoid when Writing an Abstract}

i. Communicate effectively, make the abstract readable.

ii. Avoid in-accurate reporting, such as over interpretation of research finding

iii. Avoid inconsistencies. Let there be agreement between what is in the main report and the abstract.

iv. Do not ignore law of parsimony (explain using the simplest words).

\subsection{Summary}

The chapter started with an introduction of the subject matter. Types of abstracts were included in the introduction. This is followed by the conceptual explanation of the two key variables in the topic and these are abstract and psychological research. According to Agwu, Arionu, Agbawodikeizu, Chukwu, Ebue, and Obikegna, (2016) abstract being the main focus of the chapter was illustrated using a concrete example. The structure of abstract (a typical) one was using model (fig1). After the structure comes the importance of abstract in psychology research.

The importance was broken into three stakeholders' dimensions which are the research, the researcher and the user of research outcomes. Guidelines to writing acceptable abstract were elaborately explained. Not left out of the write up is the acceptable length of an abstract. Finally the pitfalls to avoid when writing an abstract were also discussed. We are convinced that this paper will go a long way to assist your understanding of abstract and abstract writing

\section{References}

Agwu, P, Arionu, N., Agbawodikeizu, P., Chukwu, N., Ebue, M. \& Obikegna, C. (2016). Problems of Research in Nigeria. Research on Humanities and Social Sciences, 6(12), 12-31.

Chidi, R. (2013).How to Write an Abstract. www.researchcdue.com. Lagos: Nigeria.

Dooley, D. (1984).Social research Methods. N.J: Prentice-Hall Inc.

Fagbohungbe, O. B. (2010).Research Methods for Tertiary Institution and professional Bodies. Lagos: Kotleb Publishers.

Kaplan, R.M and Saccuzzo, D.P. (2001).Psychological Testing: Application and Isues. USA: Wadsworth.

Merton, R. K. (1968).Social Theory and Social Structure. New York: Free Press.

Nachmias, C. \& Nachmias, D. (1982).Research Method in the Social Science $\left(2^{\text {nd }}\right.$ Ed.). London: Edward Arnold.

Pitkin, R.M. \& Brangan, M. A. (1998). Can the Accuracy of Abstract be improved by Providing Specific Interactions? JAMA.

Hopewell, S., Clarke, D. M., Wager, E., Middleton, P., Altman, D. G. \& Schulz, K. F. (2008).CONSORTfor Reporting Randomized, P control Trials. In Journal and conference Abstract: explanation and Elaboration JAMA, 48, 49.

University of Southern California (U.S.C Libraries). Organizing your Social ScienceResearch: The Abstract. Https://lib guides.usc.edu/writing guide/abstract. 